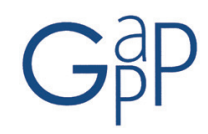

GESTIÓN Y ANÁLISIS DE POLÍTICAS PÚBLICAS, Nueva Época - N. 16, julio-diciembre 2016 - ISSN: $1989-8991$

DOI: http://dx.doi.org/10.24965/gapp.v0i16.10363

Francisco Javier Rosas Ferrusca

Universidad Autónoma del Estado de México

ferrusca200I@yahoo.com.mx

Isidro Rogel Fajardo

Universidad Autónoma del Estado de México tlatlaisi@hotmail.com

Karla Cecilia Colín Plata

Universidad Autónoma del Estado de México kccolin@mmm.com

\title{
Planeación metropolitana, políticas públicas y gobernanza territorial: Orígenes y fundamentos conceptuales en México
}

\section{Resumen}

Los actuales problemas derivados del acelerado crecimiento urbano y demográfico que han experimentado las principales ciudades de México, conducen a la necesidad de explorar la estrecha relación que debe existir entre la planeación metropolitana, las políticas públicas y la gobernanza territorial. En el caso particular de México, la escasa colaboración gubernamental a nivel inter e intrainstitucional para atender los retos de la metropolización, obligan a diseñar esquemas de coordinación horizontal y vertical que involucren la participación de los agentes sociales. Por tal motivo, el presente artículo contextualiza los orígenes y fundamentos conceptuales de estas dimensiones, cuyas aportaciones permiten perfeccionar los instrumentos que la Administración Pública en sus diferentes ámbitos puede aplicar para responder con eficiencia y eficacia a las complejas demandas de la población.

Palabras clave

Planeación metropolitana, Evaluación, Políticas públicas, Gobernanza territorial, México.

\section{Metropolitan planning, public policy and territorial governance: Origins and conceptual fundamentals in Mexico}

\begin{abstract}
The current problems derived of the accelerated growth urban and demographic that have experienced them main cities of Mexico, lead to the need of explore the close relationship that should exist between it planning metropolitan, the political public and it governance territorial. In the particular case of Mexico, the scarce collaboration level inter-governmental and intra-institutional to meet the challenges of the urbanization, is obligated to design horizontal and vertical coordination schemes that involve the participation of the social partners. By such reason, the present article contextualizes them origins and fundamentals conceptual of these dimensions, whose contributions allow perfect them instruments that it administration public in their different areas can apply to respond with efficiency and effectiveness to them complex demands of the population.
\end{abstract}

Keywords

Metropolitan planning, Evaluation, Public policy, Territorial governance, Mexico. 
«La importancia de la relación entre gobernanza, coordinación de actores y territorios ha surgido de la observación empírica por los errores de aplicación de las políticas urbanas... las cuales han conducido a evaluaciones sobre la necesidad de establecer formas de coordinación y de integración social en los espacios geográficos de aplicación de las políticas»

RAMOS CHÁvEZ y TORRES SALCIDO (2008:76)

\section{INTRODUCCIÓN}

El artículo tiene como propósito principal analizar los orígenes y fundamentos conceptuales de la planeación en México, y establece su vínculo con las políticas públicas y la gobernanza territorial. Para ello, se exponen a partir del análisis bibliográfico y el debate conceptual de diversos autores, los primeros esfuerzos realizados por institucionalizar la planeación desde su carácter técnico y centralizado en la Administración Pública mexicana. Se enfatiza en el examen histórico, en las características y retos que ha asumido el Estado moderno para responder al crecimiento acelerado de los asentamientos humanos en el territorio; ámbito enmarcado por la consolidación y surgimiento de nuevas zonas metropolitanas como la de la Ciudad de Toluca, que se ubica en la segunda posición después de la Zona Metropolitana del Valle de México, y cuya dinámica demanda el diseño y aplicación de políticas públicas acordes a su compleja situación. En este contexto, se presentan los principios y tipologías que han caracterizado la evaluación de las políticas públicas en América Latina, y se precisa la estrecha relación con la gobernanza territorial como enfoque de negociación y cooperación plural, intra e interinstitucional, que aporta grandes posibilidades para el desarrollo urbano que requieren los actores públicos, privados y sociales. Con la revisión de estos elementos, el planteamiento hipotético apunta a que las políticas públicas para la planeación metropolitana en México, no están alineadas con las prioridades de los diversos sectores de la sociedad, desfase que complica la aplicación de los principios de la gobernanza, y a su vez, fomenta la desarticulación de las estrategias de los diversos ámbitos gubernamentales para responder con eficacia a la complejidad del fenómeno metropolitano. Finalmente, se incluye un apartado de conclusiones que destaca por un lado, el panorama histórico de la planeación territorial en México y por otro, señala la utilidad y desafíos que actualmente enfrentan los instrumentos normativos para promover una verdadera participación social, a través de la innovación y flexibilidad que distingue a la nueva configuración socio espacial que apunta a los fenómenos megalopolitanos.

\section{ORÍGENES DE LA PLANEACIÓN EN MÉXICO}

Los orígenes de la planeación surgen casi a la par de la industrialización, alrededor del Siglo XX, cuando nace una preocupación acerca del diseño de las ciudades, momento en que los objetivos apuntaban hacia el poblamiento de las ciudades, buscando ventajas competitivas relacionadas con el ferrocarril, la manufactura y los servicios básicos ${ }^{1}$. La planeación pasó a ser objeto de múltiples debates que intentan explicar el tránsito de lo rural a lo urbano, y los retos de las ciudades que se encontraban en consolidación (Garza, 2006). Sin embargo, los antecedentes de la planeación en México han sido clasificados por diferentes autores de acuerdo a la temporalidad y la transcendencia de los hechos. Una de las clasificaciones generales es la elaborada por Francisco García Moctezuma (2008), quien recopila detalladamente los sucesos relacionados al institucionalismo y la planeación estratégica en tres etapas: 1900-1946 denominada de los orígenes, una segunda fase del estado de bienestar social de 1946 hasta 1982, y una fase terminal referente a la actual nombrada economía global.

La planeación tiene la capacidad disciplinaria para incidir en las políticas públicas pues aborda aspectos que suceden en el espacio físico y las relaciones que guarda con la sociedad. A principios de la década de los setenta, con el auge de la planificación, algunos de los instrumentos de iniciación fueron la regionalización, la incorporación de

1 Con el propósito de profundizar en la amplia literatura global sobre la evolución del urbanismo y del crecimiento de las ciudades en diversos continentes, se sugiere revisar, por citar sólo algunos autores, a CERDÁ, Ildefonso (1867), Teoría General de la Urbanización y Aplicación de sus Principios y Doctrinas a la Reforma y Ensanche de Barcelona. Tomo I. Imprenta Española, Madrid, España; WAGNER, Otto (1993), La Arquitectura de Nuestro Tiempo. Una Guía para los Jóvenes Arquitectos. Biblioteca de Arquitectura, El Croquis Editorial, Madrid, España; SÁNCHEZ DE MADARIAGA, Inés (1999), Introducción al Urbanismo: Conceptos y Métodos de Planificación Urbana. Editorial Alianza. Madrid, España; LAYUNO RosAS, Ángeles (2014), "Procesos y Proyectos de Configuración Estética del Espacio Urbano. La Viena de Otto Wagner”, en Arte y Ciudad, Revista de Investigación, núm. 5, abril, pp. 99-140. Madrid. Grupo de Investigación Arte, Arquitectura y Comunicación en la Ciudad Contemporánea. Universidad Complutense de Madrid. ISSN 2254-2930; SICA, Paolo (1981), Historia del Urbanismo. El siglo XX (Traducción de Joaquín Hernández Orozco). Instituto de Estudios de Administración Local, Madrid, España; CHUECA Y GoITIA, Fernando (1990), Breve Historia del Urbanismo. Alianza Editorial. Buenos Aires, Argentina; HALL, Peter (1996), Ciudades del Mañana. Historia del Urbanismo en el siglo Xx (Traducción de Consol Freixa). Ediciones del Serbal, Barcelona, España; y RoGERS, Richard (2001), Ciudades para un Pequeño Planeta, Editorial Gustavo Gili. SA, Barcelona, España. 
conceptos como polos de crecimiento, estrategias de integración, y programas con apoyo de organismos internacionales, tales como el Banco Mundial (BM) y la Organización de las Naciones Unidas (ONU). Si bien ya existían nociones sobre políticas urbanas sectoriales, como el Programa Nacional Fronterizo (1961), los primeros análisis de reordenación territorial se efectuaron según Muñoz (2007), durante la administración de Luis Echeverría (1970-1976).

Uno de los instrumentos normativos iniciadores de la planeación fue la Ley General de Población (1974)², y la Ley General de Asentamientos Humanos (1976)33, ambas dieron pauta para normar y restringir el poblamiento en las ciudades, las actividades sociales y urbanas, los limitantes de construcción y edificación. Posteriormente, se crea en 1978 el primer plan nacional de desarrollo urbano, en el cual se diseñó un sistema urbano regional de acuerdo a la funcionalidad y tamaño de las principales ciudades del país, entre las que destacaban la Ciudad de México y algunas ciudades fronterizas como Monterrey, Mexicali, y Ciudad Obregón (Muñoz, 2007). Más tarde se realizaron cambios a nivel institucional, mediante la creación de la Secretaría de Asentamientos Humanos y Obras Públicas (SAHOP), que después se transformó en la Secretaría de Desarrollo Urbano y Ecología (SEDUE), donde se crearon estrategias administrativas de planeación y programación de actividades, enfatizando en la regionalización y en los programas estratégicos de las ciudades medias.

Ante el detrimento de los instrumentos legales en materia urbana y el aumento de zonas con segregación, marginación y pobreza extrema, organismos internacionales y autoridades administrativas apostaron por la planeación para el desarrollo, concepto de carácter integral que buscaba converger todos los ámbitos de importancia nacional para alcanzar el bienestar social con programas como ONU - Hábitat y algunos elaborados a nivel microrregión regulados por instancias como la Secretaría de Desarrollo Social (SEDESOL). A pesar de los diversos planes y programas aplicados durante las últimas décadas, la planeación desde su surgimiento en México, presenta contrastes, con desequilibrios evidentes no solo en el ámbito económico, sino también en las vías hacia el desarrollo, pues prevalecen a la fecha rezagos que se han acentuado en espacios lejanos y olvidados de los principales centros urbanos.

\section{PLANEACIÓN EN EL ESTADO MODERNO: RETOS, CARACTERÍSTICAS Y TIPOLOGÍAS}

En México, la planeación se ha entendido como ejercicio primordialmente técnico y centralizado en la administración de recursos para responder a problemáticas específicas de la sociedad, las nuevas dinámicas y desafíos han exigido reevaluar la concepción tradicional, y hacer de ésta una definición flexible para su aplicación en diversos sectores. La perspectiva institucional ubica a la planeación como la etapa que forma parte del proceso de control administrativo, mediante la cual se establecen directrices, se definen estrategias y se seleccionan alternativas y cursos de acción, en función de objetivos y metas generales económicas, sociales y políticas; tomando en consideración la disponibilidad de recursos reales y potenciales, lo que permite establecer un marco de referencia necesario para concretar programas y acciones específicas a realizar en el tiempo y en el espacio (Diccionario INAP (S/F).

A lo largo de la historia la conceptualización de la planeación se ha distinguido por un carácter básicamente administrativo, teniendo como eje central la aplicación de políticas territoriales para el control del crecimiento urbano, el déficit dentro de los sistemas de movilidad urbana, el cambio excesivo de uso de suelo, y en consecuencia el gran impacto ambiental que extermina áreas de conservación y vocación ambiental, que al mismo tiempo modifica el ambiente y los elementos naturales que rodean a las ciudades. La planeación como opción para el desarrollo encarnado en la experiencia de Planes, Programas y Proyectos (PPP), promueve la generación de nuevos espacios de participación en los que sus actores han decidido sobre el rumbo de su desarrollo. Asimismo, la planeación para el desarrollo es un proceso de intervención social que implica considerar su fundamento como política pública, el mejoramiento de la capacidad individual y las dinámicas de participación (Villada, 2010).

Al respecto, Fernández Güell (1997), define la planificación estratégica de las ciudades como: «... una forma sistemática de manejar el cambio y de crear un mejor futuro posible para una ciudad. Un proceso creativo que sienta las bases de una actuación integrada a largo plazo, establece un sistema continuo de toma de decisiones que sobrelleva cierto riesgo, identifica cursos de acción específicos, formula indicadores de seguimiento sobre los resultados e involucra a los agentes sociales y económicos locales a lo largo de todo el proceso».

2 El objetivo de la Ley General de Población (1974) se orientó a realizar programas de planeación familiar a través de los servicios educativos y de salud pública de que disponga el sector público y vigilar que dichos programas y los que realicen organismos privados, se lleven a cabo con absoluto respeto a los derechos fundamentales del hombre y preserven la dignidad de las familias, con el objeto de regular racionalmente y estabilizar el crecimiento de la población, así como lograr el mejor aprovechamiento de los recursos humanos y naturales del país.

3 La Ley General de Asentamientos Humanos (1976) pretendió normar las acciones en materia de ordenamiento territorial de los asentamientos humanos y de desarrollo urbano de los centros de población de las diversas entidades federativas y los municipios. 
Otra de las concepciones acerca de la planeación es sin duda la relacionada con ubicarla como una «herramienta dirigida a la ordenación del territorio sobre la base de un análisis técnico, un consenso ciudadano y un compromiso político. El objetivo de todos los procesos de planificación radica en intervenir y corregir el desarroIlo actual. La planificación territorial requiere entonces, involucrarse en el desarrollo del espacio físico" (Nicola, 2008). Lo anteriormente dicho, cambia la concepción de la planeación, al considerarla como un instrumento y/o herramienta que se utiliza dentro del ordenamiento de los espacios, que además de tener la función de establecer estrategias y objetivos se le atribuye la función del desarrollo, y de la corrección de patologías urbanas a raíz de las sociedades modernas.

Previo a esta conceptualización, Friedmann (2001) estableció que la planeación es una forma de gestión desde la Administración Pública, destaca su propuesta enfocada a lo social, reconoce que la planificación debe reflejar las necesidades colectivas considerando los factores humanos y físicos e incluir espacios de responsabilidad, autoridad y control. Según lo describe, la planificación es una forma de gestión científica que puede analizarse desde diferentes perspectivas:

1. La dirección.

2. La administración de la institución y el buen funcionamiento.

3. La operación y el diseño de reglamentos y métodos técnicos.

Lo anterior ubica a la planificación como un proceso dinámico y elástico que no tiene un método definido y universal, sino que intercala los instrumentos para el cumplimiento de los objetivos. Así, la planificación tiene dos componentes, uno técnico y otro político, desde la parte técnica las actividades que realiza consisten en definir el problema de forma flexible, establecer un modelo y analizar la situación con el propósito de intervenir con instrumentos de política concretos diseñando soluciones, planes de acción y procedimientos de opinión y evaluación. Y en la parte política la planificación une el conocimiento científico y técnico con las acciones en el ámbito público con los procesos de orientación social y con los procesos de transformación social (Friedmann, 2001).

Por su parte, la propuesta de Healye (1997), se basa en tres tipos de planeación; la económica, que se caracteriza porque su objetivo se centra en administrar las fuerzas productivas de las naciones y regiones; la espacial y del desarrollo que se enfoca en la organización del territorio y por último, la planeación desde la administración y el análisis de políticas con objetivos centrados en la eficiencia y efectividad de las instituciones públicas. Existen sin embargo, otras clasificaciones de la planeación, una de las más reconocidas es la existencia de la planeación comunicativa, comprensiva y la planeación del desarrollo; esta tipificación ha atravesado diversas etapas en la historia, desde su origen hasta nuestros días. La primera etapa conocida como la planeación comprensiva visualiza a la planeación como análisis de la situación para definir los problemas a atender, la formulación de los objetivos, las alternativas posibles, ventajas y desventajas y definir la más conveniente para su operación. Esta fase es llamada así porque hace un análisis racional de todos los elementos y requerimientos durante el diseño, debido a ello requiere de gran cantidad de información pues todo lo establecido debe estar justificado y fundamentado (Dapena, 2003$).$

La segunda etapa está a cargo de la planeación del desarrollo, que sin duda fue una de las más significativas desde su institucionalización a finales de los años 70. Esta tipología amplia el espectro de la planeación, al ser adoptada por todos los niveles de gobierno en el estado mexicano. A través de los conocidos planes de desarrollo se inició con la aplicación de políticas territoriales que marcaron la pauta para legislar y coordinar las grandes zonas urbanas.

De acuerdo al Instituto Nacional para el Federalismo y el Desarrollo Municipal (INAFED) y la Guía Técnica para la Planeación del Desarrollo Municipal (2014), la planeación del desarrollo es una actividad de racionalidad administrativa, encaminada a la correcta convergencia de las actividades económicas con las necesidades básicas de la comunidad como la educación, la salud pública, asistencia social y vivienda, entre otros. Este tipo de planeación faculta en gran proporción a los ayuntamientos para la creación de proyectos productivos que orienten la actividad económica y social. La tercera y última etapa, es la llamada planeación comunicativa, de acuerdo a diversos autores, actualmente la planeación opera bajo estos principios y características. Esta tipología se apoya en el pensamiento sistémico, permite crear conciencia social, hace más activa la voluntad política y promueve un fuerte deseo de liberación de la base social, puede ser entendida desde la teoría de sistemas complejos, en donde los elementos de la estructura existente, en este caso actores urbanos con intereses diversos, a través de la comunicación democrática, desarrollan interacciones y surgen arreglos de orden urbano-metropolitano (Rodríguez, 2013).

Friedmann (2001), menciona que los retos de la planeación surgen a raíz de la globalización, fenómeno en el que aparecen muchas revoluciones y evoluciones principalmente en el desarrollo de las comunicaciones; históricamente la planeación espacial se ha enfocado hacia lo técnico por encima de lo social y de lo político, ya que 
se ha enfatizado en el estudio de los métodos cuantitativos y rigurosos. Por lo tanto, los nuevos procesos de configuración socio-espacial aunque parecen ser físicos, son fundamentalmente sociales, por tanto, el reto reside en la responsabilidad de conocer y desarrollar mecanismos para intervenir en la transformación de los complejos procesos de ocupación territorial.

Así, se espera que el modelo de planificación sea normativo, innovador, político y negociador, que se caracterice por planificar desde una posición descentralizada promoviendo la participación social y/o ciudadana a través de la gestión como elemento central. Dentro de un ámbito urbano, los retos de la planificación territorial apuntan hacia las siguientes premisas (Anaya, 2010).

a) Incorporar la visión de futuro a través de la prospectiva;

b) seguir innovando con los instrumentos de análisis;

c) desarrollar una efectiva participación ciudadana en el proceso de planificación;

d) lograr la concurrencia con la planificación urbanística a nivel local y con otros planes sectoriales a nivel territorial; $y$

e) establecer mecanismos efectivos de seguimiento y evaluación de los planes.

En el ámbito internacional, cabe señalar que los objetivos del milenio han influenciado los retos de la planeación territorial, puesto que se establece en múltiples acuerdos internacionales, la necesidad de diseñar un proyecto de ciudad, mejorar la vivienda haciéndola digna y de mayor calidad, fomentar la cohesión social, la inclusión y el sentido de pertenencia colectivo, crear redes de actores, alianzas y cooperaciones entre la sociedad, y por último, coadyuvar al ordenamiento del territorio de manera sustentable y equilibrada.

\section{DEBATE DE LA CONCEPTUALIZACIÓN METROPOLITANA}

El crecimiento urbano ha sido objeto de estudio inherente a la planeación, ya que debido al aumento en los perímetros urbanos surge la necesidad de la planeación como instrumento del ordenamiento territorial. Debido a ello, ha sido motivo de amplia discusión en organismos internacionales como la ONU que han puesto especial atención a estos fenómenos, pues es éste uno de los impactos en el cual se efectúa la aplicación de las políticas metropolitanas, y ha sido agente responsable del origen de la metrópolis cuyo auge detonó alrededor de 1970 y 1980 , y que ha dado pauta a que diferentes agentes institucionales e internacionales aborden las características que presentan estas formas urbanas. Ya en 1985, Harvey afirmaba que "los límites de la metrópoli, se vuelven imprecisos por su diferente capacidad de atracción y expansión sobre los territorios periféricos, límites que pueden ser delimitados o no a partir de lugares cuya población mantiene relaciones directas y subordinadas a un centro principal".

Por lo anterior, la dificultad de abordar las metrópolis constituye un asunto complejo e impreciso debido a que no existen límites físicos bien definidos, y prevalece una especulación enorme en los deberes y atribuciones metropolitanos. La expansión metropolitana ha sido tal que su caracterización como fenómeno se ha desarrollado por bloques, en razón de lo anterior «(...) el territorio de un fenómeno social o económico, asociado a una área metropolitana es equivalente a la geografía de demarcaciones jurídico administrativas específicas, ni es el mismo que el territorio de otro fenómeno» (Ugalde, 2007)4.

Uno de los principales exponentes en materia de desarrollo urbano y metropolitano en el contexto latinoamericano es sin duda Luis Unikel, que mediante diversos estudios que datan de principios de 1960, han sido base documental y guía para presentes investigaciones en materia de crecimiento urbano e impactos sociales del mismo. Para Unikel (1976), el término «metropolitano» proviene de lo urbano y es entendido como una extensión territorial que alberga a una ciudad central y unidades político administrativas contiguas que tienen características urbanas físicas similares y mantienen una interrelación socioeconómica directa y constante con la ciudad central.

El concepto de zona metropolitana fue desarrollado en Estados Unidos a partir de 1920, en México este proceso inició en la década de los cuarenta y hasta ahora se ha mostrado como el elemento de mayor jerarquía en el sistema urbano nacional, siendo el espacio físico donde se genera la mayor parte del Producto Interno Bruto del país (SEDESOL, 2005). Es así que «la metrópoli es la concentración urbana más importante de un territorio, y se ca-

4 Sobre la evolución de las ciudades, desde una pequeña aldea rural, pasando por ciudades medias y áreas metropolitanas de distinto tamaño, hasta la megaregión urbana más compleja que podamos imaginar, en un escenario global de competencia y cooperación, de retos de sostenibilidad y de compromisos de integración social, véase VERGARA GómEZ, Alfonso y DE LAS RIVAS SANZ, Juan Luis (2015), La Inteligencia del Territorio: Supercities. Ministerio de Fomento, Fundación Metrópoli. Alcobendas, Madrid, España. 
racteriza por la diversidad y elevado número de empleos que ofrece, por su protagonismo, como núcleo donde se localiza el poder político y su lugar de abastecimiento para un conjunto de bienes o servicios de menos consumo» (Zoido, 2012). Esto indica que el término metrópoli, se aplique a los centros urbanos que económicamente poseen ventajas competitivas a nivel regional, que aporten al crecimiento económico y que sean agentes centrales en la dinámica nacional.

En los últimos años los aspectos metropolitanos se han vuelto complejos e imprecisos, pero al mismo tiempo han sido punto de interés social, político y administrativo, al establecer instrumentos de regulación y consolidación urbana, además de la creación de instituciones encargadas del desarrollo metropolitano y de la calidad de la misma. Actualmente, México se distingue por contar con 59 zonas metropolitanas que concentran a 63.8 millones de personas (56.8\% del total nacional), indicador que obliga a poner especial atención a los nuevos fenómenos que acontecen en el territorio, y que se plasman en otros sectores no menos importantes como la economía y el medio ambientes.

Asimismo, es preciso destacar que existen diversos criterios para delimitar las zonas metropolitanas, uno de ellos, y el más utilizado es el número de habitantes, con una cantidad contenida en un área de 50 mil habitantes. Otro indicador son los aspectos físicos urbanos, a manera de que se encuentren contiguos, considerando a los municipios que presentan integración económica y social con el nodo central. Con el tiempo se han incorporado nuevas variables más precisas como el área que ocupan, las actividades económicas, la densidad poblacional, la distancia física entre los centros de población, entre otros.

En el caso de América Latina, las metrópolis enfrentan actualmente procesos de modernización que agudizan las desigualdades y los patrones de polarización y segregación, originando problemas de gobernabilidad que tienen un trasfondo demasiado amplio, y que no se resuelven con instrumentos normativos como hasta ahora ha operado el Estado, muchas de ellas forman parte de un complejo proceso de capitalismo global que fomenta la megalopolización.

Al respecto, Iracheta (2003) destaca que la metrópoli es un centro que ejerce preminencia económica en una región e incluso en un país, por las múltiples funciones que desempeña, pudiendo asumir éstas como producto de la globalización de la economía. La función más importante que ejercen las zonas metropolitanas radican en la diversidad de ofertas y funciones que desempeñan, algunos aspectos positivos son el empleo y los servicios y otros negativos, se reflejan en la irregularidad e informalidad del uso del suelo, además de la saturación y congestionamiento, contaminación y escasez de servicios básicos.

La metrópoli se considera en los últimos años como una unidad socio espacial de gran complejidad e intensidad de flujos e intercambios, además de sus funciones económicas y sociales deben considerar como requisito indispensable los procesos de planeación, administración y gobierno. En la postura de Huacuz (2012), los elementos centrales son los de carácter territorial, los jurisdiccionales, los sociales, los sectoriales y los de flujos, como las infraestructuras. Desde esta perspectiva, la metrópoli se ha conceptualizado como un espacio de múltiples experimentos, no solo de carácter social o económico, sino también territorial, ambiental y político, entre otros. Una de las grandes desventajas de lo metropolitano reside en no poder delimitar de forma exacta este fenómeno a pesar de los indicadores que se han establecido a lo largo del tiempo. El ámbito metropolitano no se ha institucionalizado como tal, y ha dado lugar a diversas especulaciones para atender los problemas que se generan en su interior, además que no existe una fundamentación normativa que reconozca a lo metropolitano como espacio territorial, contrariamente como ha acontecido con lo urbano y lo rural. En resumen, lo metropolitano ha sido un fenómeno de escaso interés gubernamental, cuando debiera ser de interés general para todos los actores (públicos, privados y sociales) que se interrelacionan en el territorio, pues éste es el contexto donde se desarrollan y aplican las políticas, además de representar el espacio geográfico donde actualmente residen importantes volúmenes de población. La revisión de los instrumentos de planeación en México, confirma inicialmente la hipótesis de que las políticas públicas dirigidas al control del fenómeno metropolitano, son relativamente recientes y no han logrado integrar las prioridades sociales de los principales núcleos urbanos; sus estrategias han tendido a privilegiar y detonar el surgimiento de otros conglomerados que se distinguen por la ausencia de una visión estratégica de largo plazo en su planeación, control y seguimiento.

Respecto a ello Iracheta (2003), establece que para enfrentar el fenómeno metropolitano es necesario buscar un nuevo enfoque que lo atienda desde la política, la sociedad y el gobierno; el cual debe cumplir al menos

5 De acuerdo con el INEGI (2010), de las 59 zonas metropolitanas que tiene el país destacan diez con más de un millón de habitantes: Guadalajara, Monterrey, Puebla-Tlaxcala, Toluca, Tijuana, León, Juárez, La Laguna, Querétaro y San Luis Potosí, además del Valle de México que rebasa los 20 millones de personas. Se estima que la población urbana en México pasará de 72,3\% en 2010 a 83,2\% en el año 2030; es decir, la población seguirá concentrándose en las áreas urbanas y una gran cantidad de éstas vivirá en zonas metropolitanas. 
tres objetivos: a). Una visión metropolitana, elaborada y compartida por los actores sociales bajo principios de gobernanza; b). Estructuras político-técnicas para las metrópolis, que hagan obligatoria la coordinación entre gobiernos; y c). Una planeación-acción de largo plazo e integrada. Además, plantea que la paradoja del desarrollo metropolitano exige una política de Estado hacia el territorio desde una perspectiva regional y urbanametropolitana.

\section{LA ZONA METROPOLITANA DE LA CUIDAD DE TOLUCA (ZMCT) Y EL DESARROLLO METROPOLITANO}

De acuerdo a la realidad que presenta el municipio de Toluca y su actuación dentro de la Zona Metropolitana de la Cuidad de Toluca (ZMCM), puede establecerse que ha experimentado una serie de transformaciones urbanometropolitanas desde principios de 1990 con el auge tecnológico, a la par del poblamiento de municipios conurbados al Valle de México como Ecatepec, Tlalnepantla, Naucalpan e Ixtapaluca, entre otros que alcanzaron tasas de crecimiento muy altas que propiciaron la necesidad de crear una ciudad donde se concentraran algunas de las funciones complementarias a la Ciudad de México. Toluca, debido a la importancia político administrativa que se le otorgó desde su fundación, se vislumbró como la opción más pertinente, conformándose como ciudad grande, detonando su crecimiento hacia los municipios conurbados al alrededor de 1980.

De acuerdo con Garza (2006), durante 1980 la tasa de crecimiento fue de 3.4\%, un poco menor a la media nacional, pero creció en 230 mil personas, uniéndose con la metrópoli de la Ciudad de México. Todas las ciudades que rodean la urbe mantuvieron un rápido crecimiento, especialmente Toluca (5.5\%), con la que formó una megalópolis de 19.4 millones de personas en el año 2000.

La clasificación de la calidad de las zonas metropolitanas realizada por Garza (2006), a partir de indicadores como la productividad de las ciudades, depende de una serie de factores, entre los que destacan los siguientes: la composición de su estructura económica; la eficiencia y modernización de sus empresas; la calidad de la infraestructura, equipamiento y servicios públicos; la pobreza urbana endémica; el déficit habitacional; y el subempleo urbano estructural. En conjunto, estos factores permiten obtener un índice de desarrollo humano metropolitano, basado en el Índice de Desarrollo Humano (IDH) calculado por el Programa de las Naciones Unidas para el Desarrollo en México (PNDU) en colaboración con el Consejo Nacional de Población (CONAPO). Así, las nueve ciudades con un IDH alto son: Cancún, Veracruz, Mexicali, Colima, Ciudad Juárez, Hermosillo, Pachuca, Ciudad Obregón y Monterrey. Las 22 metrópolis de desarrollo medio comprenden desde Guadalajara a Zacatecas. En este grupo se encuentra la Ciudad de México, Saltillo y Oaxaca. Finalmente, se tienen las 15 y 10 metrópolis con desarrollo humano bajo y muy bajo, entre las que figuran Tlaxcala, Cuautla, Puebla, Toluca, Irapuato, Uruapan, Celaya, entre otras (PNUD, 2014).

Durante esta evolución, de lo urbano a lo metropolitano, tienen lugar diversos procesos que alteran todas las estructuras, ya que la lógica de los mercados expansionistas ha ocasionado que se infrinja la normatividad del desarrollo urbano. Institucionalmente, algunos organismos como la Secretaría de Desarrollo Social (SEDESOL), el Consejo Nacional de Población (CONAPO) y el Instituto Nacional de Estadística, Geografía e Informática (INEGI), mediante el Programa Nacional de Desarrollo Urbano y Ordenación del Territorio (PNDUOT) 2001-2006, señalan que la megalópolis es el resultado de varias zonas metropolitanas y aglomeraciones urbanas en las regiones del país. Este tema ha sido desarrollado por diversas instituciones y han dado forma a un Sistema Urbano Nacional (SUN), el cual ha posibilitado contar con diversos instrumentos de clasificación y homologación de criterios para el diseño de políticas públicas.

Particularmente, el acelerado proceso de urbanización que enfrenta la Zona Metropolitana de la Ciudad de Toluca (ZMCT), exige una adecuada administración del suelo para privilegiar la atención de las necesidades de la población en materia de vivienda, servicios, infraestructura, equipamiento y áreas verdes, situación que demanda una mayor eficiencia y eficacia de los agentes que inciden en la urbanización; sobre todo si analizamos que de acuerdo con los resultados del Censo de Población y Vivienda (2010), el Estado de México registra el mayor crecimiento absoluto de la última década en el país, al concentrar 2.1 millones de personas más que en el año 2000 , incremento que evidencia la relevancia del tema al consolidarse como la entidad federativa de mayor volumen demográfico (13.5\% del total nacional).

Lo anterior, adquiere significativa importancia al comparar las tendencias de crecimiento futuro para los próximos diez años. De acuerdo con el Plan Regional de Desarrollo Urbano del Valle de Toluca (2005), se estima que la población de la Región del Valle de Toluca a mitad del año 2020 será de 2'191,926 habitantes, lo cual significa que albergaría del orden de los 542 mil nuevos habitantes en los próximos diez años. Las tendencias actuales de crecimiento y distribución de la población, indican que para el año 2020, el Estado de México crecerá del orden de los 4.5 millones de habitantes; de los que se programa que el $72.6 \%$ se asentaría en los municipios del Valle 
Cuautitlán-Texcoco (Región del Valle Cuautitlán - Texcoco), 14.6\% en los municipios del Valle de Toluca (657,000 habitantes) y el $12.8 \%$ en los municipios del resto del Estado.

\section{RED DE POLÍTICA URBANA EN EL TRANSCURSO DE LA ETAPA EVALUATIVA}

Las políticas públicas son aquellas encaminadas a resolver problemas públicos. El enfoque tiene dos vertientes, la política gubernamental y el de política pública de forma genérica. La primera de ellas alude a «decisiones públicas, decisiones de gobierno, las cuales tienen implicaciones directas e indirectas en la relación gobernantesgobernados» y la segunda, se refiere al proceso de involucramiento de la sociedad dentro de la construcción de las políticas públicas (Velasco, 2009). Otros autores como Marco Moreno (2009), establecen que las políticas son cursos de acción definidos por el gobierno, que tienen como fin último el resolver un área relevante de asuntos de interés público, en la cual suelen también participar los actores de origen privado. La perspectiva de González (2003) define a una política como «una secuencia intencionada de acción seguida por un actor o conjunto de actores a la hora de tratar con un asunto que los afecta... y son aquellas desarrolladas por cuerpos gubernamentales y sus funcionarios» ${ }^{6}$.

El enfoque territorial de acuerdo con Pradilla (1990), ubica a la política territorial «... como una serie de acciones que buscan organizar y transformar las relaciones entre territorio y sociedad, una decisión asumida democráticamente y compartida por la mayoría de los ciudadanos, cuyo objetivo es la satisfacción creciente de las necesidades materiales y sociales de la población». Así, la política pública territorial es la más apta para entender el desarrollo metropolitano, a pesar de que atraviesa por puntos críticos de diseño, aplicación y seguimiento, y falta de continuidad, ya que ésta debe combinar instrumentos y conceptos con mayor capacidad de prevención y metas realistas.

La política urbana actúa dentro de un marco de política pública y surge donde los problemas urbanos convergen con las problemáticas administrativas, por lo que se convierten también en mediadoras y reguladoras de la ciudad. Según Brugué y Gomá (2002), las políticas urbanas constituyen la dimensión espacial del estado bienestar en control del espacio. A pesar de que la política urbana tiene su implicación en el espacio, los productos que de ella derivan tienen un impacto social, económico, ecológico, administrativo, financiero y político, es por ello que la importancia de ésta en el territorio es crucial para que su desarrollo durante su formulación y su operación sean adecuados y se logren objetivos multidimensionales.

El concepto de política urbana de acuerdo con Brugué y Gomá (2002), se concibe como la actuación del gobierno local en las ciudades desde dos enfoques, la convergencia institucional y la naturaleza de las ciudades como conjunto de aspectos o de elementos urbanos. Las políticas urbanas tienen una relación directa con los procesos de gobernación y de democracia institucional, por ello Uvalle (2005), señala que las políticas públicas son el principal contenido de la gobernabilidad en las ciudades, menciona que gobernar por políticas implica responder a los intereses ciudadanos, reconocer la pluralidad en las sociedades modernas y atender los intereses del territorio.

Es importante destacar que desde la perspectiva moderna de la Administración Pública el término «Policy network», mejor conocido como «red de políticas», ha cobrado relevancia institucional a partir de 1970, y se ha consolidado como un elemento de la gobernanza, este término se refiere a la noción de red que se convierte en un esquema de representación de las relaciones entre actores durante la construcción de una política pública, en la caracterización de una nueva forma de gobierno que trasciende la coordinación política ejercida primordialmente por el Estado o la coordinación a través del mercado (Jiménez, 2008). Dentro de las sociedades modernas, el Estado ejerce el poder público por medio de estas redes de políticas, que si bien antes eran de carácter mono institucional, dentro de los últimos 20 años, han direccionado su funcionamiento para ser de carácter integral y retroalimentarse a partir de diferentes ámbitos y organismos públicos.

Desde un punto de vista analítico, pueden distinguirse cinco etapas en las políticas públicas: origen, diseño, gestión, implementación y evaluación. La primera etapa se genera cuando se decide hacer frente a un problema y subirlo a la agenda pública; la segunda cuando se estructura la acción gubernamental; la tercera cuando se gestionan todos los apoyos políticos presupuestarios; la cuarta cuando la política pública se pone en acción, y la última cuando se revisan los efectos. En este sentido, la evaluación es concebida como una de las últimas fases, aunque algunos autores la consideran una interrelación de las anteriores (Salcedo, 2011).

6 En un artículo previo se examina la importancia que adquieren las políticas públicas y su impacto en algún sector de la sociedad, por lo que su análisis no sólo resulta útil sino fundamental por parte de los gobiernos. Para tal efecto véase RoSAS FERRUSCA, Francisco Javier (2013), “Políticas Públicas: sentido, utilidad y argumentación”, en Revista IAPEM, núm. 86 (septiembre-diciembre, 2013), pp. 57-78, México. D. F. 


\section{NOCIONES CONCEPTUALES DE EVALUACIÓN}

En 1972 se planteaba que la palabra evaluación era tan elástica que podría cubrir juicios de toda índole. En la década de los ochenta las escuelas de evaluación consideraban que era un proceso que servía para determinar el mérito, costo y valor de los programas. En la actualidad, la evaluación es un procedimiento analítico clave que abarca la mayoría de las disciplinas intelectuales y prácticas (Salcedo, 2011). El Instituto Nacional de Administración Pública (INAP), define a esta etapa como la fase del proceso administrativo que hace posible medir en forma permanente el avance y los resultados de los programas, para prevenir desviaciones y aplicar correctivos cuando sea necesario, con el objeto de retroalimentar la formulación e instrumentación (Diccionario INAP, S/F).

La perspectiva de Salcedo (2011), define a la evaluación de las políticas públicas «como la valoración de la acción emprendida por los poderes públicos de la agenda pública, tiene como principal destinatario a la comunidad de los actores políticos sin preocuparse de la comunidad científica. El objetivo es valorar los resultados e impactos de una política con la pretensión de racionalizar la toma de decisiones». Sin embargo, este concepto no ha sido únicamente complejo para la federación, países como Colombia y algunos otros de América Latina, han sido también participes dentro de la conceptualización y aplicación de la evaluación de políticas. Ejemplo de ello es el Departamento Nacional de Planeación (DEEP) en Colombia, que define a la evaluación como una investigación sistemática y objetiva aplicada en la cadena de resultados que tiene como finalidad mejorar el diseño, implementación y ejecución de una política a través de la toma de decisiones. De igual forma, organismos internacionales como la Organización para la Cooperación y el Desarrollo Económico (OCDE), han establecido lineamientos conceptuales que funcionan como guía en diversos espacios, ubicando a la evaluación como una apreciación sistemática y objetiva de un proyecto, programa o política en curso o concluido, el cual consta de un proceso que determina el valor o la significación de una actividad.

La evaluación no es solo una etapa del proceso administrativo para la elaboración de políticas, forma parte también de varias disciplinas, como lo es la planeación estratégica, algunas ciencias exactas y biológicas. Por lo que la importancia de la evaluación es crucial dentro del desarrollo de las ciudades, y aún más dentro de la planificación de las metrópolis, ya que sin una correcta evaluación nunca se tendrá un conocimiento sólido y certero del desarrollo, éxito o fracaso de las políticas en el territorio.

La evaluación lleva a su mando varias utilidades, algunas de las más sobresalientes dentro del campo del desarrollo local y las políticas públicas son de acuerdo con Ramos (2008), las siguientes: a). Funge como generadora de información, de los avances, estancamiento, dificultades o retrocesos; b). Es posible llevar a cabo un control administrativo legal y financiero; c). Racionaliza y re orienta la forma de decisiones públicas; y d). Sirve como una guía de referencia de las prácticas de las instituciones y su correcto funcionamiento.

\section{CARACTERÍSTICAS, PRINCIPIOS Y TIPOLOGÍAS EVALUATIVAS}

Los tipos de evaluación comprenden una clasificación de la que numerosos estudiosos han hecho uso para racionalizar mejor esta etapa, poder discernirla en funciones, características y fines metodológicos. La clasificación que a continuación se presenta sintetiza las más utilizadas dentro de la Administración Pública en América Latina.

CUADRO 1. TIPOLOGÍAS EVALUATIVAS DE POLÍTICAS PÚBLICAS

\begin{tabular}{|c|c|}
\hline Tipología & Descripción \\
\hline \multicolumn{2}{|r|}{ Evaluador } \\
\hline Interna & $\begin{array}{l}\text { Se realiza por el personal del programa encargado delagestión eimplementación, } \\
\text { presenta ventajas pues se encuentra más apegada al conocimiento de los } \\
\text { mecanismos de elaboración. }\end{array}$ \\
\hline Externa & $\begin{array}{l}\text { Es elaborada por especialistas externos contratados por la Administración } \\
\text { Pública con la información generada. }\end{array}$ \\
\hline \multicolumn{2}{|r|}{ Función } \\
\hline Sumativa & Tiene por objeto proporcionar información para mejorar el objeto evaluado. \\
\hline Informativa & $\begin{array}{l}\text { Suministra información sobre la toma de decisión de continuación o suspensión } \\
\text { de un programa. }\end{array}$ \\
\hline
\end{tabular}




\begin{tabular}{|c|c|}
\hline Tipología & Descripción \\
\hline \multicolumn{2}{|r|}{ Contenido } \\
\hline Diseño & $\begin{array}{l}\text { Analiza la racionalidad y coherencia del programa, trata de verificar la bondad del } \\
\text { diagnóstico, los objetivos y la problemática. }\end{array}$ \\
\hline Aplicación/Gestión/Proceso & $\begin{array}{l}\text { Examina la forma en que se gestiona y ejecuta el programa, y valora el grado de } \\
\text { implicación de los gestores. }\end{array}$ \\
\hline Resultados e impactos & $\begin{array}{l}\text { Trata de conocer el grado de logro de los objetivos y a que coste se lograron } \\
\text { dentro de un carácter de tiempo, recursos humanos y monetarios. }\end{array}$ \\
\hline \multicolumn{2}{|r|}{ Temporalidad } \\
\hline Ex ante & $\begin{array}{l}\text { Se realiza antes de ejecutar el plan, política o programa, tratando de adecuarlo a } \\
\text { las necesidades, anuncia sobre los mecanismos de gestión y seguimiento. }\end{array}$ \\
\hline Intermedia & $\begin{array}{l}\text { Se lleva a cabo a la mitad de la ejecución, consiste en el análisis de los datos y } \\
\text { permite introducir modificaciones en el diseño o ejecución. }\end{array}$ \\
\hline Ex post & $\begin{array}{l}\text { Se ejecuta una vez finalizado el programa, permite medir el éxito o fracaso de un } \\
\text { programa, su capacidad de flexibilidad y adaptación a una realidad cambiante. }\end{array}$ \\
\hline
\end{tabular}

Fuente: Elaboración propia en base en la Guía para la evaluación de políticas públicas (S/F).

\section{LA GOBERNANZA COMO INSTRUMENTO DE CONVERGENCIA TERRITORIAL}

El enfoque de la gobernanza surge a partir de diferentes paradigmas epistemológicos y su importancia por definirla, aplicarla y conservarla dentro de los estados, ha sido creciente en los últimos años, ya que muestra en su interior un interés por la coordinación y la construcción de diálogos y acuerdos locales y regionales. La gobernanza aparece primeramente como un instrumento de negociación y de cooperación entre una pluralidad de actores tanto de la sociedad civil, del sector económico y del mercado, como del Estado. En este sentido, Velásquez (2006) considera que la gobernanza se refiere a «»los procesos colectivos que determinan en una sociedad cómo se toman decisiones y se elaboran normas sociales con relación a asuntos públicos con base en: a). la conflictividad; b). los actores estratégicos; c). los espacios o nodos de conflictividad; d). las reglas que rigen la relación entre los actores $\mathrm{y}, \mathrm{e}$ ). las dinámicas que determinan la conflictividad en el tiempo».

Hoy en día, este tema ha sido objeto de un gran argumento y controversia social y administrativa, debido a que se ha cuestionado en diferentes ocasiones su existencia, verdadera aplicación y metodología, sin llegar nunca entre los aportes teóricos que se han elaborado a su favor, a conclusiones y hallazgos sólidos, que puedan servir de guía para actuales y futuras investigaciones que apliquen de manera sistémica este principio.

Los orígenes de esta corriente teórica datan desde el inicio de la ciencia política y los principios de la democracia a principios del Siglo XIX. Sin embargo, los antecedentes contemporáneos se dirigen al nuevo regionalismo, que se manifiesta en las regiones territoriales, identificando las redes de intercambio que se establecen entre los actores y las instituciones que dan forma a las políticas públicas independientemente de que éstas sean de carácter público o privado. Para Porras (2007), la teoría de la gobernanza se propone cuando los estados entraron en crisis financiera y de legitimidad, lo que ocasiona que exista una confusión entre las funciones públicas y privadas, teniendo actores que siguen criterios de los mercados y actores privados con responsabilidades públicas. En consecuencia, la gobernanza se pone en práctica por la presencia de redes mixtas, donde los actores sociopolíticos operan políticas comunes no porque lo dicte la normatividad, sino para actuar conforme al desarrollo sustentable de los lineamientos considerados del bien público.

A diferencia de los estudios metropolitanos convencionales, el nuevo regionalismo establece que la coordinación debe involucrar al sector privado en el diseño e implementación de las políticas, al mismo tiempo que para el nuevo regionalismo, la influencia de los actores no gubernamentales sobre las políticas regionales, se incrementa a través de la colaboración voluntaria en redes informales (Porras, 2007).

\section{CARACTERÍSTICAS Y PRINCIPIOS DE LA GOBERNANZA}

El esquema de la gobernanza contemporánea debe responder a valores democráticos como la libertad, igualdad, participación, transparencia, rendición de cuentas, y se caracteriza en la opinión de Uvalle (2012) por: 
a) La autonomía de los organismos y movimientos de la sociedad civil ante el aparato político y administrativo del Estado;

b) la apertura de la estructura y funcionalidad del Estado para evitar la maximización de beneficios de los políticos y los administradores;

c) la participación de la sociedad en las tareas de gobernar para disminuir las jerarquías administrativas y burocráticas que alejan a los Estados de los ciudadanos;

d) el aumento de los procesos de corresponsabilidad con la dinámica de los actores gubernamentales y actores no gubernamentales;

e) el incremento de la responsabilidad de los Estados ante los ciudadanos respecto a su desempeño institucional, para administrar mejor los recursos escasos y mejorar la calidad de las políticas públicas; y

f) el aumento de los procesos de cooperación sociedad-Estado con base en redes.

Los principios de la gobernanza se relacionan con la organización vertical multinivel (principios de responsabilidad, coordinación y cooperación), horizontal (entre territorios -principio de cooperación- y entre sectores -principio de coherencia-) y participación (grupos de interés, con el objetivo de mejorar las rutinas en la toma de decisiones con el propósito de maximizar los efectos gracias a un correcto diseño, aplicación y seguimiento de las políticas con impacto sobre la sociedad y los territorios para poder alcanzar la meta del desarrollo territorial sostenible y el objetivo de la cohesión territorial (Farinós, 2008).

En la visión de la nueva gobernanza, la cooperación del Estado y la Sociedad Civil guían a la Administración Pública en una actividad complementaria, coordinadora y responsable de estimular y fomentar las iniciativas individuales, asociativas y las redes de organizaciones. Por ende, hay prácticas relacionadas con las contralorías sociales, los presupuestos participativos, los comités de evaluación social, las auditorías ciudadanas, los consejos ciudadanos y los observatorios ciudadanos (Uvalle, 2012).

Las prácticas antes mencionadas se han consolidado como nuevos mecanismos al mismo tiempo de regulación y evaluación, que además de ser eficaces funcionan para fortalecer la democracia y gobernanza entre los actores territoriales, velando por la organización horizontal y la gobernabilidad de las metrópolis. La gobernanza pasó de referirse meramente a la acción del gobierno o ejercicio del gobierno en una región, a «el marco de reglas, instituciones y prácticas establecidas que sientan los límites y los incentivos para el comportamiento de los individuos, las organizaciones y las empresas» (Mayorga, 2007).

Por su parte, el PNUD define a la gobernanza como «el ejercicio de la autoridad económica, política y administrativa para administrar los asuntos de un país a todos los niveles de gobierno; comprende los mecanismos, los procesos y las instituciones a través de las cuales los ciudadanos y los grupos articulan sus intereses, ejercen sus derechos legales, cumplen sus obligaciones y resuelven sus diferencias». La revisión de los instrumentos normativos permite afirmar que el avance de la gobernanza en los gobiernos metropolitanos mexicanos es aún limitado y escaso debido al complicado contexto urbano que interviene, hay fragmentación político administrativa y muchos actores emergentes, en donde los primeros ejercen hegemonía y los más poderosos cuentan con más y mejor organización e información. Legislando con regímenes institucionales deficientes donde otros actores históricos influyen con más eficacia y legitimidad sobre las gestiones (Rosas, 2012).

\section{GOBERNANZA TERRITORIAL}

Algunas de las características y principios de la gobernanza se relacionan con la organización vertical multinivel, y coordinación horizontal entre territorios y sectores. También se añaden algunos principios de acceso a la información y apertura, el funcionamiento sistémico en las instituciones formales e informales para llegar a la meta del desarrollo territorial sostenible (Farinós, 2008). En la gobernanza territorial, estos principios se aplican generalmente en la coordinación horizontal, formando redes de actores en el territorio, todos estos deberán tener una apertura y flexibilidad para la realización de tareas específicas de acuerdo al rol en el que se encuentren, actualmente, estas redes están fragmentadas y poco interconectadas entre sí.

Una de las vertientes de la gobernanza aplicada a los espacios urbanos es la gobernanza territorial, aparece así como un nuevo modo de articular y de regular la compleja arquitectura derivada del encajamiento de diferentes escalas de decisión, al mismo tiempo que como ámbito de reflexión y de acción para generar nuevas formas de desarrollo que conduzcan hacia la consecución de una cohesión territorial sostenible. La Red de Observación de la Planificación Territorial Europea (ESPON) hace mención de la gobernanza territorial como el «proceso de organización y coordinación de actores para desarrollar el capital territorial, con el objeto de mejorar la cohesión territorial en los diferentes niveles del espacio» (Abad, 2010). 
La gobernanza territorial puede ser entendida desde dos vertientes. Una de ellas la ubica como la aplicación de los principios y características, y otra como la puesta en marcha de ésta, mediante la creación y análisis de redes de planificación y gestión, que darán como resultado dinámicas territoriales innovadoras y compartidas, respaldadas por múltiples actores que comparten objetivos e interacciones en la arena pública (Farinós, 2008). Por su parte, Pérez (2013), entiende por gobernanza metropolitana a la «...forma en que los gobiernos, grupos organizados y residentes en una zona metropolitana determinada pueden asociarse con el propósito de controlar o regular su comportamiento y el funcionamiento o provisión de servicios para el área en su conjunto».

En este contexto, Lefèvre (2005) menciona que la gobernanza metropolitana destaca los valores de negociación, asociación, participación voluntaria y flexibilidad en la construcción de nuevas estructuras, el autor muestra un punto interesante de la gobernanza como el resultado de un proceso consultivo. Conviene destacar que durante el 2003, Hooghe y Marks realizaron una clasificación de la gobernanza multinivel, la cual ha tenido un gran reconocimiento dentro de la Administración Pública, ya que elabora un análisis de las diferentes formas en que se ha manifestado en distintos países. Las características de las tipologías de gobernanza se enuncian en el siguiente cuadro.

CUADRO 2. TIPOS DE GOBERNANZA MULTINIVEL

\begin{tabular}{|l|l|}
\hline \multicolumn{1}{|c|}{ TIPO I } & \multicolumn{1}{c|}{ TIPO II } \\
\hline Jurisdicciones con propósitos múltiples & Jurisdicciones con propósitos específicos \\
\hline Límites territoriales sin traslapes & Límites territoriales con traslapes \\
\hline Jurisdicciones organizadas en niveles & Sin límite en el número de niveles \\
\hline Diseño amplio y perdurable & Diseño flexible \\
\hline
\end{tabular}

Fuente: Elaboración propia en base en HOOGHE, L., y MARKS, G. (2003).

Existe otra modalidad de gobernanza, que en términos urbanos está cobrando relevancia desde hace algunas décadas, ya que países como Brasil han optado por esta forma de convergencia y coordinación metropolitana, denominada «sin gobierno metropolitano» que es un esquema de cooperación que tiene como principal característica la fragmentación político administrativa, promueve la participación social representativa y una rendición de cuentas más transparente. No son obligatorias y no existe un nivel de gobierno que lo sustente, solo existen cooperaciones locales y algunos casos institucionales que administran y coordinan las acciones entre los integrantes (Pérez, 2013).

En México cada vez más han surgido intentos de gobernanza que pretenden involucrar a los diversos agentes y sectores de la sociedad. Sin embargo, se ratifica que aún no logra consolidarse como una herramienta esencial para la planificación y ordenamiento de los asentamientos humanos en el territorio, representa un reto para la Administración Pública federal, estatal y municipal, sobre todo para garantizar que las políticas de desarrollo urbano y metropolitano apliquen criterios específicos en las fases de diseño, ejecución y evaluación?

\section{CONCLUSIONES}

Los aspectos presentados brindan un panorama histórico-institucional de cómo han evolucionado los conceptos relacionados con el proceso de desarrollo urbano y metropolitano particularmente en México. La planeación tradicional no ha sido funcional en las últimas décadas, la planeación estratégica y del desarrollo, que han sido posturas metodológicas, si bien dieron respuesta a diversas problemáticas a inicios de los años 90, hoy en día ya no pueden permanecer en el mismo esquema de funcionamiento; sobre todo en lo que concierne a la administración y gestión urbana. Las instituciones y organismos que se encargan de la planeación urbana no se han consolidado de manera totalitaria, pues no se tiene una idea clara de las necesidades, de los retos y atribuciones que se poseen en materia metropolitana.

7 El análisis comparativo de los alcances y limitaciones de la gobernanza metropolitana en el ámbito internacional rebasa los objetivos de este trabajo. No obstante, al respecto existe abundante bibliografía, en el caso europeo es posible consultar HEINELT, Hubert \& KüBLER, Daniel (2005), Metropolitan Governance: Capacity, Democracy and the Dynamics of Place. Routledge Taylor \& Francis Group/ECPR Studies in European Political Science. New York, E. U., y RAO, Nirmala (2007), Cities in Transition: Growth, Change and Governance in Six Metropolitan Areas. Routledge Taylor \& Francis Group/ECPR Studies in European Political Science. New York, E. U. Para el caso latinoamericano se puede profundizar a través de la revisión de RosAs FerRusCA, Francisco Javier, SÁNCHEZ GonZÁLEZ, José Juan y CALDERÓN MAYA, Juan Roberto (2015), “Estudio comparado: gobernanza y buenas prácticas para el desarrollo de la administración territorial en Europa y América Latina”, en SoRANI, Valentino y ALQUICIRA, María Luisa (Editores). Perspectivas del Ordenamiento Territorial Ecológico en América y Europa, Sociedad Internacional de Ordenamiento Territorial y Ecológico (ISLPEP), México; y SCHTEINGART, Martha y PíREZ, Pedro (2014), Dos grandes metrópolis latinoamericanas: Ciudad de México y Buenos Aires, una perspectiva comparativa. El Colegio de México. México. 
Más allá de prevalecer una visión de largo plazo, las instituciones creadas recientemente para atender los retos del desarrollo urbano son resultado de las presiones de agentes sociales, a favor de la descentralización entre los sectores de desarrollo social y de obras públicas. No obstante, las instituciones debieran surgir como respuesta a las necesidades detectadas y con el objetivo de ser suficientemente válidas y eficientes para otorgarles el presupuesto necesario para el cumplimiento de sus objetivos.

La planeación territorial, al considerarse como un instrumento de coordinación, negociación y convergencia, resulta sumamente útil en la etapa de la evaluación de políticas públicas, al sectorializar el territorio en congruencia con lo establecido en los planes de desarrollo urbano y regional. Uno de los retos a los que se enfrenta la planeación prospectiva, es precisamente hacer de los planes de desarrollo, en cualquiera que sea su carácter, instrumentos realmente operativos, donde la estructura permita la participación, la innovación y flexibilidad para el ordenamiento territorial, y que no solo sean escritos extensos puramente normativos. El no establecer lineamientos precisos para delimitar y definir las metrópolis constituye también una barrera para la acción pública, dentro de la operación y diseño de políticas, pues no se conocen las realidades metropolitanas de manera exacta y delimitada. La nueva configuración socio espacial del Siglo XXI obliga a considerar cada vez más, a las redes físicas y funcionales con un enfoque más amplio, dinámico y variado que garantice la participación y cooperación intermunicipal, aunado a la asignación de incentivos que fomenten la cooperación en proyectos de impacto regional.

La planeación prospectiva hace alusión a la continua evaluación dentro del ciclo de las políticas públicas y en el ámbito urbano debe evolucionar y transformarse, a fin de que todos los actores se encuentren igualmente interesados y comprometidos en ella, trasladando así el concepto de política gubernamental al de política pública incluyente en las grandes ciudades. Por ello, la gobernanza debe aplicar sus principios éticos y dejar de ser simplemente un discurso político; en México debe materializarse y ser evaluada de la misma manera que se lleva a cabo en otros enfoques de la Administración Pública y de las ciencias sociales.

Si bien, el cumplimiento del estado de derecho es responsabilidad y atribución del estado mexicano, es preciso subrayar que deberá adoptar un carácter facilitador, administrador y negociador para atender el fenómeno metropolitano. Es de suma importancia para éste adoptar nuevos principios y retos para consolidar una Administración Pública moderna, eficiente y congruente con los instrumentos de regulación y monitoreo que demanda el bienestar urbanístico en la misma proporción que otros rubros como el desarrollo económico o social, en donde el factor metropolitano mantiene una estrecha vinculación. Así, lo nuevos modelos de gobernanza que México demanda deben transitar de esquemas jerárquicos unilaterales, hacia aquellos que propicien una democracia realmente efectiva en el ámbito local que garanticen una mayor participación y compromiso de la ciudanía, contexto en el que la planeación territorial es determinante.

Está claro que en el territorio nacional y particularmente en el Estado de México, las políticas urbanas, la disponibilidad de recursos financieros y la forma de administrar el territorio no han logrado responder a los desafíos que los conglomerados urbanos y metropolitanos presentan, ni los marcos explicativos ofrecen aún elementos para definirlos ni comprenderlos con precisión, situación que los convierte en áreas de oportunidad para el desarrollo de políticas públicas desde diversas ópticas y perspectivas. Los grandes desafíos exigen atender, como agente de cambio desde el ámbito institucional, la complejidad del fenómeno metropolitano a través de planes, programas y proyectos que verdaderamente integren las demandas de los diferentes sectores sociales; diseñen mecanismos de seguimiento y evaluación de un sistema de indicadores de desarrollo urbano metropolitano, de información geográfica metropolitana y de gobernanza metropolitana integrada; promuevan la conformación de alianzas intermunicipales; exploren la pertinencia de transitar hacia las agencias de desarrollo metropolitano; actualicen los planes sectoriales, de desarrollo urbano municipal y de ordenamiento territorial de la ZMT con una visión de largo plazo; propongan esquemas de coinversión público-privada orientadas a prevenir la expansión desordenada e irregular de las actividades urbano metropolitanas; gestionen recursos crediticios para la realización de proyectos de impacto regional-metropolitano; convoquen a las instituciones públicas, privadas y sociales para la construcción de acuerdos multisectoriales dirigidos a la planeación y gestión de estrategias que conduzcan a un desarrollo urbano metropolitano ordenado, incluyente, competitivo y sustentable.

\section{BIBLIOGRAFÍA}

AbAd ARAGón, Luis (2010), Gobernanza y Desarrollo Territorial: Una perspectiva geográfica. Grupo de Estudios sobre Desarrollo Urbano. Madrid, España.

AgUilar VilLANUEVA, Luis F. (2007), “El aporte de la política pública y de la nueva gestión pública a la gobernanza”, en Revista CLAD Reforma y Democracia, núm. 39. México. 
ANAYA GonzÁlez, Lorena (2010), “La Planeación metropolitana integral como política pública: Retos. oportunidades y lineamientos para su diseño y formulación”, en Revista del Instituto de Administración Pública del Estado de México (IAPEM), núm. 77. México.

BRUGUÉ QUIM, Gomá y otros (2002), "La Gobernabilidad de las Ciudades y los Territorios en la Sociedad de las Redes", en: SUbIRANTS, Joan (coordinador), Redes, Territorio y Gobierno, Barcelona, Universidad Internacional Menéndez Pelayo de Barcelona y Diputación de Barcelona/ Red de Municipios.

CONSEJO ESTATAL DE POBLACIÓn (2012), Zona Metropolitana del Valle de Toluca: Aspectos Sociodemográficos. México.

DAPENA RIVERA, Luis Fernando (2003), Núcleos de Vida Ciudadana, Racionalidades y Coyunturas en la Gestión de un Proyecto Urbano. Universidad Nacional de Colombia, Facultad de Arquitectura. Medellín, Colombia.

Departamento Nacional de Planeación (2014), Guía Metodológica para el Seguimiento y la Evaluación a Políticas Públicas. Sistema Nacional de Evaluación de Gestión y Resultados, SINERGIA: 20 Años. Bogotá, Colombia.

E. MAYORGA F. y CORDOVA (2007), Gobernabilidad y Gobernanza en América Latina. Working paper NCCR NorteSuer.

FARINÓs DASI, Joaquín (2008), “Gobernanza Territorial para el Desarrollo Sostenible: Estado de la Cuestión y Agenda”, en: Boletín de la Asociación de Geógrafos Españoles, núm. 46. Valencia, España.

FERNÁNDEZ GüELL, José Miguel (1997), Planificación Estratégica de Ciudades, Barcelona: Editorial Gustavo Gili.

Ferreiro, Alejandro y Silva, FELIPE (2010), Evaluación del impacto y calidad de las políticas públicas: Hacia una agenda independiente. Informe Económico. México.

FriedmANN, John (2001), Planificación en el ámbito público. Del conocimiento a la acción. Instituto Nacional de Administración Pública (Ministerio de Administraciones Públicas). Madrid, España.

GARCía MoctezumA, Francisco (2010), “La Planeación del desarrollo regional en México (1990-2006)”, en Revista Scielo investigación geográfica, núm. 71, 2010 [fecha de consulta: 02 de febrero de 2016]. Disponible en: http://www.scielo.org.mx/scielo.php?script=sci_arttext\&pid=S0188-46112010000100009\&Ing=es\&nrm=iso. ISSN: 0188-4611.

GARZA VILLAREAL, Gustavo (2006), "Características socioeconómicas y gestión de las metrópolis en México”, en Colección Legislando la Agenda Local: Importancia social, económica y territorial de los nuevos fenómenos metropolitanos, Centro de Estudios Sociales y de Opinión Pública (CESOP), México.

GERARDO, Nicola (2008), La planificación territorial. Sistema de portales profesional-open source, 2014 [fecha de consulta: 22 de enero de 2016]. Disponible en: http://asambleaconstituyente.gov.ec/blogs/gerardo_ nicola/2008/07/16/la-planificacion-territorial.

GonzÁlez TAChIQuín, Marcelo (2003), El Estudio de las Políticas Públicas: Un Acercamiento a la Disciplina. Universidad Autónoma de Chihuahua, Chihuahua, México.

HARVEY, David (1985), The Urbanization of Capital. Studies en the History and Thoery of Capitalist Urbanization. Baltimore, Johns Hipkins University Press.

HEALYE, Patsy (1997), Collaborative Planning; Shaping Places in Fragmented Societies, Vancouver. Press University of British Columbia.

HÉRAS JIMÉNEZ, Héctor (2002), Transformaciones en la estructura territorial: el caso de la zona metropolitana de la Ciudad de Toluca 1999-2000. Toluca, Estado de México. Facultad de Planeación Territorial, Universidad Autónoma del Estado de México.

HOOGHE, L., \& MARKS, G. (2003), “Unraveling the central state, but how? Types of multi-level governance”. American Political Science Review, 97 (2), 233-243. DOI: 10.1017/So003055403000649.

HowARD, Ebenezer (1971), "Ciudades Jardín del Mañana”, en AYMonino, Carlo (ed.), Orígenes y Desarrollo de la Ciudad Moderna, Gustavo Gili, Barcelona, España.

Hoyos CAStillo, Guadalupe (2005), "Marco Empírico Histórico de la Dimensión Física del Proceso de Urbanización de las Ciudades de México y Toluca”, en: Quivera, año 7, núm. 2005-2, Toluca. CEPLAT/FaPUR, UAEM.

HuACUZ-ElíAs, Rafael de Jesús, Reseña de "Políticas públicas para gobernar las metrópolis mexicanas" de Iracheta Cenecorta, Alfonso, Economía, Sociedad y Territorio [en línea] 2012, XII (enero-abril) [Fecha de consulta: 20 de febrero de 2016]. Disponible en: http://redalyc.org/articulo.oa?id=11122403011. ISSN: $1405-8421$.

INSTITUTO NACIONAL DE ADMINISTRACIÓN PÚBLICA (INAP). S. f. Glosario de términos más usuales en la administración pública federal. Secretaría de Hacienda y Crédito Público. México.

instituto Nacional de EstadísticA, Geografía e INFORMática (2010), Censo de Población y Vivienda, México, INEGI.

IRACHETA CEnecortA, Alfonso, "Gobernabilidad en la Zona Metropolitana del Valle de México". Papeles de Población [en línea] 2003, 9 (abril-junio) [Fecha de consulta: 20 de febrero de 2016]. Disponible en: http:// www.redalyc.org/articulo.oa?id=11203609. ISSN: $1405-7425$. 
JIMÉNEZ B., WILLIAM, Guillermo (2008), "El enfoque de las políticas públicas los estudios sobre gobierno: Propuestas de encuentro", en Revista del CLAD Reforma y Democracia, núm. 41. México.

LefÈvRE, Christian (2005), "Gobernabilidad democrática de las áreas metropolitanas. Experiencias y lecciones internacionales para las 89 ciudades latinoamericanas", en: ROJAS, Eduardo; CUADRADO-ROURA, Juan; GÜELL, José Miguel FERNÁNDEZ (orgs.), Gobernar las metrópolis. Washington, D. C. BID -Banco Interamericano de Desarrollo-, 2005, cap. 4, pp. 195-261 [fecha de consulta: 28 de julio de 2016]. Disponible en http://www. economia.unam.mx/cedrus/descargas/Gobernar_las_metrópolis.pdf. ISBN: 1597820156.

Ley General de Asentamientos Humanos (1976), Última reforma DOF, 24-01-2014, Cámara de Diputados del H. Congreso de la Unión, México, D. F.

Ley General de Población (1974), Última reforma DOF, 1-12-2015, Cámara de Diputados del H. Congreso de la Unión, México, D. F.

MARTín MESA, Antonio y MERINERo Rodrícuez, Rafael (2008), "Evaluación y planificación estratégica territorial”. Planificación estratégica territorial: Estudios metodológicos. Consejeria de Gobernación, Dirección de Administración Local. Andalucia, España.

MAYORGA, F. \& CóRDOVA, E., (2007), Gobernabilidad y Gobernanza en América Latina. Working Paper NCCR NorteSur IP8, Ginebra.

MinISTERIO De POLÍtICA TERRITORIAL Y AdMINISTRACIÓN PÚBLICA MUNICIPAL (2010), Fundamentos de Evaluación de Políticas Públicas. Agencia Estatal de Evaluación de las Políticas Públicas y la Calidad de los Servicios. Madrid, España.

MORENo, Marco (2009), Proceso y tensiones en la formación de políticas. Curso Planificación y gestión estratégica para las políticas públicas. Santa Cruz, Bolivia.

OBREGón, Davis, SARAH, Alejandra (2007), Planeación para el desarrollo humano y bases metodológicas para su instrumentación. Análisis de las experiencias en Andalucía y Jalisco. Universidad Politécnica de Madrid. España.

OsUNA, José Luis (2014), Guía para la evaluación de políticas públicas. México.

Plan de Desarrollo del Estado de México (2011-2017). Gobierno del Estado de México, Estado de México.

Plan Estatal del Desarrollo Urbano del Estado de México (2008), Gaceta del Gobierno, Toluca de Lerdo, México, lunes 19 de mayo, núm. 93.

Plan Regional de Desarrollo Urbano del Valle de Toluca (2005), núm. 28, vol. 1, Secretaría de Desarrollo Urbano y Vivienda, Estado de México.

PÉREZ TORRES, Daniel Enrique (2013), Las zonas metropolitanas de México: Estructuración urbana, gobierno, gobernanza. Universidad Autónoma Metropolitana. México, D. F.

PINEDA, D. Saúl (2011), Gobernanza territorial e integración regional en Colombia: La experiencia de BogotáCundinamarca en los gobiernos locales en la construcción del futuro de los paises. América-Europa de Regiones y Ciudades (AERYC).

PORRAS, Francisco (2007), "Teorías de la gobernanza y estudios regionales", en Revista Secuencia, num. 69. México. DOI: 10.18234/secuencia.voi69.1022.

PRADILLA COBOS, Emilio (2009), "La arena política en lo metropolitano ¿limitante u oportunidad para la gobernabilidad", en: El Legislativo ante la gestión metropolitana, Roberto EIBENSCHUTZ HARTMAN y Ligia GonzÁlez GARCí́ DE AlBA (coord.). H. Cámara de Diputados, LX Legislatura, Universidad Autónoma Metropolitana-Xochimilco. Editorial Porrúa, México.

Programa de las Naciones Unidas para el Desarrollo (PNUD) (2014), Índice de Desarrollo Humano Municipal en México: Nueva Metología. México.

RAMíREZ DE LA CRUZ, Edgar E. "Instituciones y gobernanza metropolitana: una primera aproximación al caso de México". Estudios Demográficos y Urbanos [en línea], 2012, 27 (mayo-agosto) [fecha de consulta: 20 de febrero de 2016]. Disponible en: http://www.redalyc.org/articulo.oa?id=31226408006. ISSN: 0186-7210.

RAMOS ChÁvez, Héctor Alejandro, TORRES SALCIDO, Gerardo (2008), "Gobernanza y territorios. Notas para la implementación de políticas para el desarrollo", en Revista Mexicana de Ciencias Políticas y Sociales. UNAM. Mayo-agosto. México, D. F.

Rosas Ferrusca, Francisco Javier, CAmpos Alanís, Héctor, Calderón Maya, Juan Roberto, "Elementos conceptuales para el análisis de la gobernanza territorial”. Quivera [en línea], 2012, 14 (julio-diciembre) [fecha de consulta: 20 de febrero de 2016]. Disponible en: http://www.redalyc.org/articulo.oa?id=40126859001. ISSN: 1405-8626.

SALCEDO, Roberto (2011), Evaluación de políticas públicas. Siglo XXI. México, D. F.

Secretaría de Desarrollo Social, Consejo Nacional de Población e Instituto Nacional de Estadística, GEOGRAFÍA E INFORMÁTICA (2004), Delimitación de zonas metropolitanas. México, D. F.

SERnA GUZMÁn, Carolina, VILLAdA Ríos, María Alejandra. "Innovando Estrategias metodológicas", en planeación para el desarrollo Revista Bitácora Urbano Territorial [en línea], 2010, 17 (julio-diciembre) [fecha de consulta: 20 de febrero de 2016]. Disponible en: http://www.redalyc.org/articulo.oa?id=74816991009. ISSN: 0124-7913. 
SOLARTE PAZOS, Leonardo (2004), Evaluación de políticas públicas en el contexto del Estado liberal. Universidad del Valle. Cali, Colombia.

UGALDE VICENTE (2007), “Sobre el gobierno en las zonas metropolitanas de México”. Estudios Demográficos y Urbanos [en línea], 2007, 22 (mayo-agosto) [fecha de consulta: 23 de febrero de 2016]. Disponible en: http:// www.redalyc.org/articulo.oa?id=31222206. ISSN: 0186-7210.

UNIKEL, Luis (1976), El desarrollo urbano en México, diagnóstico e implicaciones futuras, El Colegio de México.

UNIKEL LUIS, et al. (2014), Ensayo sobre el desarrollo urbano de México: La dinámica de crecimiento de la ciudad de México, s.f., 2014 [fecha de consulta: 15 de enero de 2016]. Disponible en: https://etnografiaurbana.files. wordpress.com/2010/06/luis-unikel.pdf.

UVALLE BeRRONES, Ricardo (2012), “La administración pública en los imperativos de la gobernanza democrática”, en Revista Covergencia, vol. 19. México.

Velasco ZaPATA, Francisco (2009), Políticas gubernamentales. Política mexiquense, 2014 [fecha de consulta: 10 de febrero de 2016]. Disponible en http://politicamexiquense.blogspot.mx/2009/12/politicas-gubernamentales. html.

VELÁSQUEZ M., Elkin (2006), La gobernabilidad y la gobernanza de la seguridad ciudadana. Centro de Investigación sobre Dinámica Social. Colombia.

VILLADA Ríos, María y Serna G. C. Alejandra (2010), “Innovando estrategias metodológicas en planeación para el desarrollo", en Revista Bitácora Urbano Territorial, vol. 01. Colombia. 